\title{
Establishing the Learned Effect of Repeated Wingate Anaerobic Tests
}

\author{
JOSEPH R. SECREST, KYLIE-ANN LOUW, ERIC J. JONES, and MALCOLM T.
}

WHITEHEAD

Human Performance and Fitness Laboratory; Department of Kinesiology and Health Sciences; Stephen F. Austin State University; Nacogdoches, TX

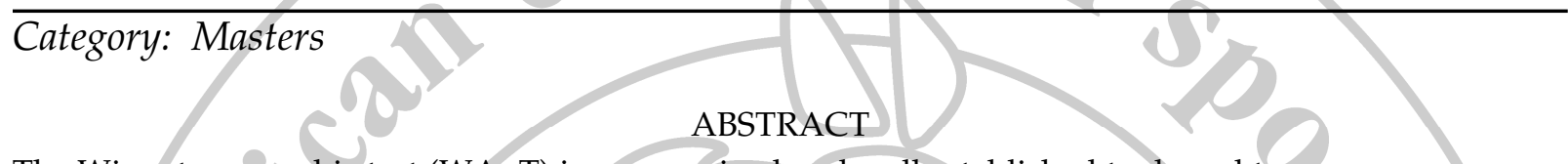

The Wingate anaerobic test (WAnT) is a recognized and well established tool used to measure power output, muscular endurance and fatigue. Changes within the aforementioned variables attributable to a learning effect could reduce the reliability of these measures. The purpose of this study was to establish the number of WAnT trials needed to produce a learned effect and reliability of that effect. Ten apparently healthy college-aged males participated in five trials of 30-second cycle ergometer sprints separated by a minimum of 72 hours. Resistance for trials was calculated at $7.5 \%$ of each respective subjects' weight. This study tracked the changes in Peak Power (PP), Mean Power (MP) over time. Paired samples t-test using 2 tails revealed PP increased on all trials (2-5) when compared to trial $1(+57 \mathrm{~W}$, $+69 \mathrm{~W},+68 \mathrm{~W},+48 \mathrm{~W})(\mathrm{p}=0.02, \mathrm{p}=0.03, \mathrm{p}=0.04, \mathrm{p}=0.14)$ respectively, and indicated peak wattage at trial 3. $\mathrm{MP}$ also increased on all trials (2-5) when compared to trial $1(+32 \mathrm{~W},+49 \mathrm{~W},+39 \mathrm{~W},+32 \mathrm{~W})(\mathrm{p}=0.01$, $\mathrm{p}=0.01, \mathrm{p}=0.02, \mathrm{p}=0.05$ ) respectively, demonstrating mean peak wattage at trial 3 . These results suggest that a learning effect is present within PP and MP until the third trial of the WAnT. All but $30 \%$ subjects elicited peak PP and MP during trial 3. Thereby, suggesting that when performing WAnT, utilizing less than 3 practice trials might elicit significant power increase due to this learned effect. Further research should be conducted in order to support the findings from the present investigation.

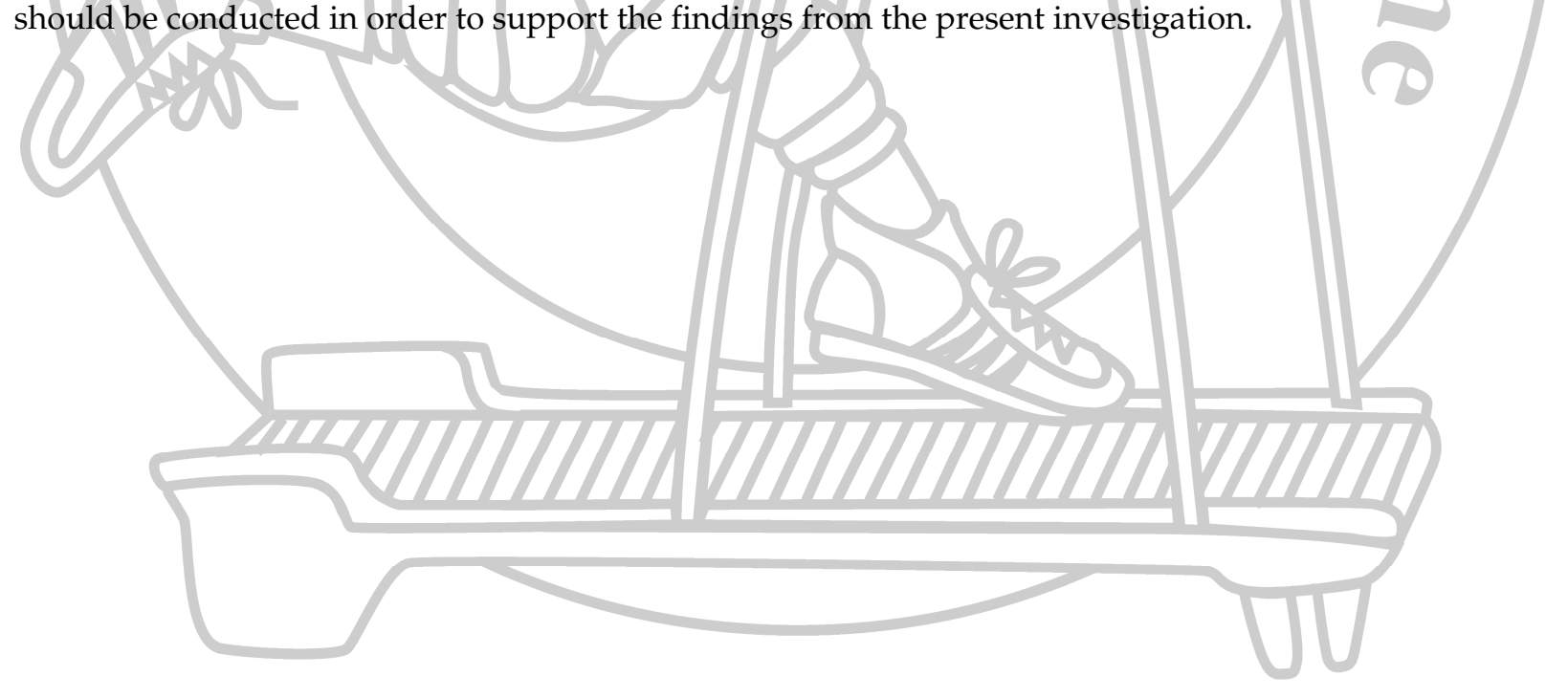

